ARCHIVO ESPAÑOL DE ARTE, LXXXVI, 344

OCTUBRE-DICIEMBRE 2013, pp. 291-310

ISSN: 0004-0428

\title{
LAS REPRESENTACIONES DE DON GASPAR DE HARO Y GUZMÁN, VII MARQUÉS DEL CARPIO: RETRATOS, ALEGORÍAS Y EMBLEMAS ${ }^{1}$
}

\author{
María López-Fanjul y DíEz del CorRal \\ Staatiche Museen zu Berlin
}

Este artículo está dedicado a estudiar una serie de retratos de Don Gaspar de Haro y Guzmán, VII Marqués del Carpio, especialmente importantes por su relación con el dibujo, las alegorías, los emblemas y la búsqueda de la fama a través de los libros.

Palabras clave: Gaspar de Haro y Guzmán; Marqués del Carpio; Giacinto Brandi; Sebastiano Baldini; Dibujo; Alegoría; Emblema; Retrato.

\section{IMAGES OF DON GASPAR DE HARO Y GUZMÁN, VII MARQUIS OF CARPIO: PORTRAITS, ALLEGORIES AND EMBLEMS}

The author studies various portraits of Don Gaspar de Haro y Guzmán, 7th Marquis of Carpio, and analyses the strong links that they had with his interest in drawing, emblems, allegories, and the search for fame through books.

Key words: Gaspar de Haro y Guzmán; Marquis of Carpio; Giacinto Brandi; Sebastiano Baldini; Drawing; Allegory; Emblem; Portrait.

En 1688 Fabritio Pinto lamentaba la muerte del virrey de Nápoles don Gaspar de Haro y Guzmán (1629-1687), a quien ya no podría honrar "delineando su retrato con los azules más intensos que las pinturas de Apeles jamás hubiesen conocido"2.

Don Gaspar, hijo de Don Luis de Haro (1598-1661) y Catalina Fernández de Córdoba (*1610), fue embajador en Roma (1675-1682) y virrey en Nápoles (1683-1687) donde murió, en palabras

\footnotetext{
${ }^{1}$ El contenido de este artículo forma parte de mi tesis doctoral, financiada con una beca predoctoral por la Fundación Oriol-Urquijo: 'Collecting Italian Drawings in Seventeenth-Century Spain: the Marqués del Carpio's Collection', tesis doctoral inédita, The Courtauld Institute of Art, Londres, 2011.

2 'Se mai vi fù alcuno celebre Oratore, che desidarasse con aurea eloquenza nell'Areopago d'Atene, ò nel Senato di Roma, le due più rinomate accademie de saggi, ele schole più erudite dell'arte del ben parlare, comprarsi gli applausi di famoso dicitore; tal uno sarei io hoggi, ò Signori, no per acquistar fama di facondo, ma per poter con gli azuri più vivaci, che mai colorisse Apelle le sue dipinture, dilinear l'effigie dell'Eccellentiss. Signore D. GASPARRE D'HARO, Marchese del Carpio, Conte Duca d'Olivares, Vicerè, e Capitan Generale di questo Regno'. Pinto, 1688: 5.
} 
de F. Haskell, habiendo asentado las bases fundamentales que elevarían el virreinato a la primera línea de la Europa intelectual ${ }^{3}$. Heredero político de su padre y de su tío abuelo el Conde-Duque de Olivares (1587-1645), es internacionalmente conocido como el VII Marqués del Carpio. Hábil político, Carpio fue también uno de los coleccionistas más importantes de la España Barroca siendo, además, el primer gran coleccionista español de dibujos.

El interés por el dibujo que el Marqués demostró desde su juventud abarca campos mucho más amplios que el tradicional coleccionismo en álbumes ${ }^{4}$. Carpio lo utilizó como instrumento político, reunió una exquisita colección que mandó enmarcar para decorar las paredes de sus palacios y fue también su mecenas ${ }^{5}$. Este artículo está dedicado a analizar un grupo de sus retratos a través de las estrechas relaciones que tuvieron con el dibujo, la emblemática, y la búsqueda de la fama a través de los libros.

'Confieso que debo al arte la majestad con que hoy triumpho"6 afirmó Carpio, consciente del éxito de su política cultural y de la capital importancia que ésta había jugado en el establecimiento de la imagen pública de la que disfrutó al final de su vida. Este proceso empezó durante su juventud en Madrid, donde el Marqués comenzó a utilizar el arte en su ascenso político, donde estuvo especialmente influenciado por el ejemplo de Don Luis y de Olivares, y donde en 1662 tuvo lugar el punto de inflexión de su carrera política: el atentado del Buen Retiro; episodio que terminaría para siempre con sus aspiraciones a convertirse en privado real ${ }^{7}$.

De su padre, Carpio aprendió de primera mano la importancia política que el coleccionismo de arte tenía en la corte de Felipe IV. A pesar de que todavía falta un estudio detallado sobre las colecciones de Don Luis, los estudios de M. Burke y M. J. Muñoz sobre las compras en la almoneda de Carlos I de Inglaterra revelan una muy interesante colección de pinturas y muestran el papel fundamental que Don Luis jugó en la compra de obras para el Rey ${ }^{8}$. Del Conde-Duque de Olivares, Carpio aprendió la importancia de las 'políticas culturales', del arte como herramienta política a gran escala. Olivares fue el arquitecto del programa político destinado a renovar la gloria de España a través de las artes; cuyos primeros pasos, como ha estudiado J. Elliott, fueron la metamorfosis de Felipe IV en el parangón del príncipe culto y la creación de una brillante vida cultural que ayudase a crear el sentimiento de una monarquía revitalizada ${ }^{9}$.

Tras ser condenado culpable del atentado contra la Familia Real en el Buen Retiro, Carpio dedicó el resto de su vida a recuperar el favor de los monarcas. Uno de los caminos que eligió para ello fue la divulgación de sus logros políticos y culturales acompañados de su retrato. Esta práctica alcanzó su momento más importante durante los años del Marqués como embajador de España en Roma,

\footnotetext{
${ }^{3}$ Haskell, 1971: 192.

${ }^{4}$ En los últimos años, tanto historiadores españoles como italianos han comenzado a prestar mayor atención a la figura de Carpio como coleccionista de dibujos, pero centrándose exclusivamente en el análisis de los álbumes conservados: Cacciotti, 1994. Marías, 2003: 209-219. Frutos, 2005b: 5-21. Prosperi Valenti Rodinò, 2008: 3-33. Farina, 2009: 339-362; 2010: 183-198. López-Fanjul, 2010: 463-481.

${ }^{5}$ Para un estudio detallado véase López-Fanjul Díez del Corral, 2011: 104-196.

${ }^{6}$ Anselmi, 2008: 187.

${ }^{7}$ En Febrero de 1662 Carpio fue acusado de mandar colocar un barril de pólvora bajo los asientos de la Familia Real en el teatro del Buen Retiro. Su participación en el caso nunca fue probada pero, aún así, fue declarado culpable. Su sentencia a muerte fue conmutada por diez años de exilio y dos de servicio como soldado en la guerra contra Portugal, durante los cuales fue hecho prisionero. Cuatro documentos relatan estos hechos: Biblioteca Nacional de España (de ahora en adelante BNE): ms. 11011, fols. 58-70; ms. 10596, fols. 47-99v; ms. 10695, fols. 158-175. Real Biblioteca de Palacio: VIII/9390, fols. 274-290. Ver también: para la condena BNE ms. 10596; para la prisión BNE ms. 10695; para el proceso BNE ms. 11011.

${ }^{8}$ Muñoz, 1996: 198-201. Burke, 2002: 87-106. Para Don Luis véase también: Malcolm, 1999.

${ }^{9}$ Como resultado de esta política, el rey de España se convertiría en ejemplo de nobleza ante los demás monarcas europeos y, por extensión, su corte sería la más brillante de todas. Elliott, 1986: 168-178.
} 
donde comenzó a utilizar abiertamente el arte como doble herramienta propagandística ${ }^{10}$. Por un lado nos encontramos con la difusión de la colección de Carpio y de su persona como entendido en arte ${ }^{11}$. Ejemplo de ello son los dibujos y grabados que mandó hacer y distribuir de las mejores obras de su colección ${ }^{12}$. Y por otro, destaca el uso de la obra de arte en papel como instrumento para plasmar sus logros sociales. Por ejemplo, el Marqués celebró numerosas veces su éxito social en festejos que fueron estampados; como las fiestas en honor de la onomástica de la reina María Luisa obra de Philip Schor, la Acanea romana de 1677, y otras estampadas por Antonio Bulifon ${ }^{13}$. Parte de este segundo tipo de propaganda artística fue la invención y distribución del propio retrato (real o alegórico) de Carpio.

En el siglo XVII, numerosos nobles, siguiendo el ejemplo de los monarcas, entendieron la importancia de hacer grabar y distribuir su retrato como manera de controlar y hacer crecer su fama, en particular cuando vivían fuera de la Península ${ }^{14}$. En palabras de F. Haskell, la mera existencia del retrato era el hecho histórico ${ }^{15}$.

Como ha explicado F. Checa, la imagen artística en los palacios españoles del Barroco se miraba a través de un sistema conceptual basado en una doble metáfora de los textos de Don Diego de Saavedra Fajardo y de Federico Zuccaro ${ }^{16}$. A esta imagen se le confería un valor propagandístico, pedagógico, educativo, formador y persuasivo en el alma del gobernante, quien vería en sus antepasados un ejemplo a seguir ${ }^{17}$. Trasladando la observación de las galerías reales a las nobles, es importante señalar que el Conde-Duque de Olivares, por ejemplo, fue el personaje más retratado en la colección de su sobrino-nieto, registrándose hasta tres representaciones diferentes en el inventario carpiano de la almoneda madrileña ${ }^{18}$.

Los retratos de representantes de la Corona española en territorio extra peninsular tenían una función didáctica y política. El mérito del buen gobernante se reconocía al transformarse en modelo a seguir por sus sucesores. En este contexto, como han estudiado V. Manfrè e I. Mauro, nacen las series de retratos de los representantes del poder español en Italia ${ }^{19}$. Éstos reflejaban la misma gravedad característica de las representaciones de los monarcas de la Casa de Austria, metáfora de dignidad política y moral.

10 Sobre este tema véase, entre otros: Elliott, 1985: 15-42. Para un estudio puntual sobre el uso de la propaganda en la creación de la imagen política de un noble español en el siglo XVII: Pérez Preciado, 2009 : 477-506.

11 Sobre las diferencias entre la figura del entendido y del conocedor en la España del siglo XVII ver: Cano de Gardoqui, 2001: 128. Sobre la ejemplificación de estas nociones en Carpio ver: MorÁn, Portús, $1997: 51$.

12 Véase López-Fanjul Díez del Corral, 2011: 165-169.

13 Diferentes pruebas de la estampa de la onomástica de la Reina han sido ya publicadas: SALERNO, 1967: 111; FAGIOLO DEll' Arco, CARAndini, 1977: vol. 1, 296. A éstas podemos añadir otra prueba dedicada a Catalina, hija de Carpio (Biblioteca Bartolomé March, de ahora en adelante BBM, B83-C-13) y otra conservada en la Biblioteca Británica T71(5). En todas las estampas se lee "honorare il di natalitio", pero debieron de ser hechas en conmemoración de la onomástica de la Reina (hasta la fecha el día de San Luis se celebra el 25 de Agosto), quien nació el 27 de Marzo de 1662 . Para un estudio de la Acanea de 1677 véase: Frutos, 2005a: vol. 1, 476-479 (tesis doctoral leída en la Universidad Complutense y publicada en 2010 como El Templo de la Fama. Alegoría del Marqués del Carpio. Citamos por la tesis doctoral, ya que el apartado de dibujos ha sido reducido drásticamente en la publicación); FAGIOLO DEL' ARCO, 1999: 165. Sobre, por ejemplo, las fiestas en honor de la reina María Luisa grabadas por Antonio Bulifon, véase: FruTos, 2005a: vol. 1, $1158-1161$.

14 Sobre los retratos Reales y la propaganda: MARIN, 1981. Sobre el retrato en la España del siglo XVII: PorTús, 2004. Brown, 1999: 321-338. Sobre retratos Reales: Davies, 1998: 69-79. Bodart, 2003: 89-114. MARTín, 2004. Soler, 2010. Pascual Chenel, 2010. Sobre el significado del coleccionismo de retratos en los monarcas españoles véase Bass, $2008: 7$.

15 'the mere existence of the portrait was the historical fact'. HASKELL, 1993: 60.

16 CHECA, 1999: 51-52.

17 CheCA, 1999: 57. Checa argumenta a partir de la obra Errores celebrados de Juan de Zabaleta (Madrid, 1653).

18 Burke, Cherry, 1997: 861 (lote 608), 866 (lote 767), 870 (lote 964).

No se registra, sin embargo, ningún retrato de su padre Don Luis, de quien se sabe que apenas fue retratado. Sobre el tema véase BASSEGODA, 2002-2003.

19 Manfrè, Mauro, 2010-2011. 
Las primeras series de gobernantes españoles en Italia fueron las de los gobernadores de Milán, herederos en su tipología del retrato de Corte borgoñón difundido en el siglo XVI por las obras de Tiziano y Antonio Moro ${ }^{20}$. En Nápoles, esta práctica se retrasará hasta mediados del siglo XVII y estará estrechamente unida a la imagen de fuerza y poder que el conde de Oñate (virrey de 1648 a 1653 ) quiso transmitir a través del palacio napolitano ${ }^{21}$.

El Marqués del Carpio fue plenamente consciente del poder de publicar su propia imagen y de la importancia que esta práctica había jugado en la historia. Aproximadamente el $25 \%$ de los cuadros registrados en el inventario de su almoneda (1689), eran retratos y en su propia biblioteca, guardaba libros tales como "Efigies de los príncipes de Holanda y Burgundia" o "Retratos de los hombres ilustres franceses que estan Pintados en la Galeria del Palacio del Cardenal Richelieu"22. Los inventarios registran un retrato suyo, obra de Andrés Smidt ${ }^{23}$. Además, según De Dominici, Giovanni Maria Morandi le retrató en Roma y se conoce la intención del pintor romano Vincenzo Noletti de pintar su retrato póstumo para la serie de virreyes del palacio napolitano ${ }^{24}$. Pero, hasta la fecha, del Marqués sólo nos han llegado representaciones en papel. Aunque algunos han sido utilizados anteriormente para ilustrar diversos estudios, estos retratos nunca han sido analizados ni como conjunto, ni como producto y herramienta de la política cultural de Carpio.

Como veremos a continuación, los retratos en papel fueron producidos a lo largo de toda la vida del Marqués, tanto en España como en Italia. La complejidad de su composición crecerá, sin embargo, desde su llegada a Roma. A partir de entonces, el retrato seguirá siendo una clara herramienta propagandística, pero también se convertirá en instrumento de experimentación artística y entrará a formar parte tanto del mecenazgo carpiano como de la colección de dibujos. En general, estas representaciones pueden agruparse en dos grupos territoriales: los retratos realizados en España y aquellos producidos en Italia. Mientras que el primer conjunto se compone de una única obra de diseño muy simple, el segundo puede dividirse en dos subgrupos más complejos. El primer subgrupo está compuesto por una serie de retratos laudatorios, de simbología inspirada en los logros culturales y políticos de Carpio y cuya iconografía está inspirada en un primer dibujo-retrato realizado en Roma por Giacinto Brandi. El segundo grupo, denominado aquí como emblemas-retratos, ilustra la intención del Marqués de hacer pública su fama a través de la alegoría y la experimentación artística.

El grupo de retratos hechos en España está formado por una única estampa que ilustra el primer volumen del libro Sangre Triunfal de la Iglesia: en las vidas, que sus gloriosos martyres por el nombre, y fe de Iesu Christo Redemptor Nuestro heroicamente dieron (fig. 1) ${ }^{25}$. Como veremos a continuación, la importancia de esta obra no reside tanto en la propia representación de Carpio, como en el hecho de que ilustre la dedicatoria de un libro.

${ }^{20}$ Manfré, Mauro, 2010-201: 108. Sobre el tema, véanse Kusche, 1991 y Falomir, 2008.

${ }^{21}$ Manfré, Mauro, 2010-201: 117.

22 Archivo Histórico de Protocolos de Madrid (de ahora en adelante AHPM): protocolo 9819, ff. 879v y 880. Archivo Casa de Alba, Madrid (de ahora en adelante ACA): caja 302, f. 180.

${ }^{23}$ Los inventarios también registran dos retratos de su hija Catalina y dos de sus mujeres. De la primera, María Antonia de la Cerda $(† 1669)$, incluso mencionan un retrato a dibujo obra también de Smidt (Para un estudio de este dibujo en la colección Carpio véase: López-FanJul, 2010).

ACA caja 302, ff. 36-36v (BURKe, CHERRY, 1997: 741, nos. 208-210); AHPM: protocolo 9819, f. 1042v, 1063v (BuRKE, CHERRY, 1997: 856, nos. 462-463, 465; 873, no. 1053).

${ }^{24}$ De Dominici, 2006: 519. MuÑoz, 2008: 303, nota 634.

${ }^{25}$ Aguafuerte y buril. 284 x 192 mm. Bartolomé de Villalba, 1672. Estampa dibujada y grabada por Marco Orozco, fechada en 1670 En la Biblioteca Nacional de España (de ahora en adelante BNE) se conservan tres ejemplares: la imagen recortada del retrato de Carpio ( $\mathrm{IH} / 4229 / 5)$ procedente de la antigua Colección Carderera; la estampa suelta BNE 3/55719; y sin recortar como parte de la portada del vol. 1 (7/12253). El retrato de Carpio está en la p. 1. Barcia, 1901: 392, no 864-3, Páez, 1966-1970: 1545-32. El segundo volumen está dedicado al Marqués de Aytona. 
Formalmente, el retrato se encuentra en la parte inferior de la estampa, acompañado del escudo del Marqués y rodeado por una filactelia. En ésta se reproduce parte del versículo 1 del salmo 110 de los Libros Poéticos y Sapienciales de la Vulgata, que es una alabanza a las grandes obras de Dios: "Confitebor tibi De. [domine] in toto corde meo: in consilio Iustorum \& congregatione" (Doy gracias a Yahvé de todo corazón, en el consejo de los justos y en la comunidad ${ }^{26}$. Carpio, representado de medio busto, aparece vestido de negro con cuello blanco y con la cruz de Alcántara adornando su pecho (orden de la que era Comendador Mayor). A la derecha del retrato aparecen San Lorenzo, San Esteban y San Sebastián, y a su izquierda Santa Inés, Santa Lucía y Santa Catalina; todos ellos parte del grupo de los primeros y más importantes mártires cristianos. Presiden la composición en la parte superior, la Inmaculada con el Niño

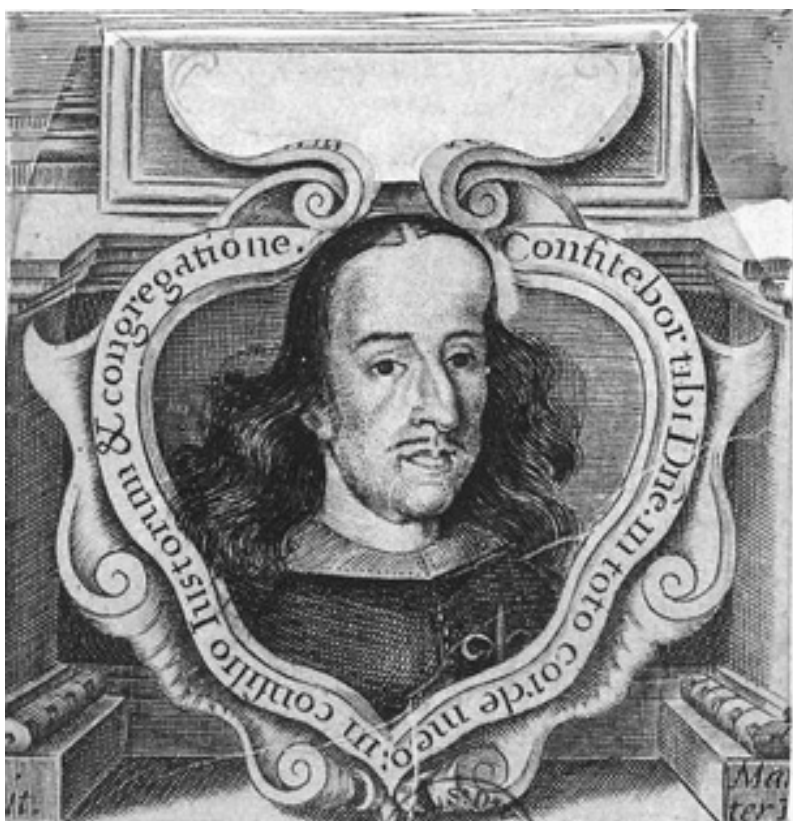

Fig. 1. Retrato de don Gaspar de Haro y Guzmán 1670 Marco Orozco. Aguafuerte y buril. Biblioteca Nacional de España. acompañados de San Andrés, San Pedro, San Bartolomé, San Jerónimo y dos Papas, enmarcados también por una leyenda. El texto de ésta también copia un pasaje de la Vulgata, más concretamente parte del verso 9 del versículo 2 de la Epístola de San Pablo a los hebreos, que subraya el reconocimiento a los mártires cristianos que, como Cristo, murieron por su fe: "Videmus Iesum propter passionem mortis glia [gloria] \& honore coronatum" (a Jesús, le vemos coronado de gloria y honor por haber padecido la muerte $)^{27}$. Como se puede fácilmente interpretar, la composición de esta estampa está directamente relacionada con el contenido del libro y la aparición de Carpio se reduce estrictamente a su condición de dedicatario. Anuncia, sin embargo, la importancia que el papel y el libro, como medio y como objeto, tendrán para el Marqués.

Las bibliotecas se habían convertido en un signo de distinción entre la nobleza española del siglo XVII y los libros fueron utilizados para ensalzar la fama de nobles y benefactores ${ }^{28}$. Durante sus años en la Península, libros como el que nos ocupa fueron dedicados a Carpio, junto a otros como las Academias morales de las musas ${ }^{29}$. Como veremos a lo largo de este estudio, esta práctica continuó incluso después de la muerte de Carpio incluyendo, como en este caso, sus retratos y alegorías. La propia biblioteca del Marqués ocupó un lugar primordial entre sus aficiones, sus colecciones y en la construcción de su propia imagen. Fue contenedor de sus gustos, espejo de sus ambiciones y retrato de sí mismo ${ }^{30}$. Es más, estaba presidida por un busto del propio Carpio cuya presencia podemos com-

26 Traducción al español de la Biblia de Jerusalén, 1976: 799.

27 Traducción al español de la Biblia de Jerusalén, 1976: 297.

${ }^{28}$ Sobre la nobleza y los libros dedicados véase, por ejemplo: VÁlgoma, 1966. BouzA, 2009: 29-46.

${ }^{29}$ BNE R/736. GÓMEZ, 1660.

${ }^{30}$ La biblioteca del Marqués del Carpio está siendo estudiada por el Prof. F. Bouza y por F. Vidales. Para un estudio de los dibujos que se guardaban en la biblioteca véase López-Fanjul Díez del Corral, 2011: 177-196. 
parar con la descripción que F. Checa hizo de los retratos de los monarcas en la biblioteca de El Escorial: "viene a significar tanto el interés [...] por ofrecer una imagen de protección a la cultura, como el propio ennoblecimiento que esta última proporciona a los poderosos" ${ }^{\text {"31. }}$.

Tras este primer ejemplo realizado durante la etapa española del Marqués, contamos con un segundo grupo de retratos estampados durante sus años en Italia. Seis de ellos están especialmente relacionados entre sí, pues su iconografía tiene origen en un dibujo perdido de Giacinto Brandi. La obra fue comisionada por Carpio en 1682, posiblemente para ser utilizada como imagen oficial tras llegar su nombramiento como nuevo virrey de Nápoles. De hecho, se convirtió en uno de los dibujos preferidos del Marqués quien, según sus inventarios, lo mandó enmarcar y colgar en el Palazzo di Spagna ${ }^{32}$. Estaba realizado en papel azul a sanguina, carboncillo y albayalde, decorado con un marco dorado y protegido por un cristal.

La importancia de este dibujo reside en el artista y material elegidos. Brandi fue uno de los personajes claves del barroco romano; a quien no nos sorprendería ver trabajando más intensamente para el Marqués pero quien, sin embargo, sólo contribuyó con una segunda obra, otro dibujo, a las colecciones carpianas ${ }^{33}$. El medio utilizado sorprende por su originalidad y modernidad, ya que el dibujo fue valorado como creación independiente y, como veremos a continuación, loado como uno de los mayores tesoros de la colección de Carpio. No perderá, además, su condición práctica de modelo para la producción de diversas estampas.

Hemos podido relacionar el dibujo de Brandi con estas estampas gracias a los siete sonetos que le dedicó el poeta italiano Sebastiano Baldini en 1684 y que vieron la luz en su obra Il Tempio della $\mathrm{Fama}^{34}$. El volumen está compuesto por siete partes, cada una de ellas dedicada a uno de los proyectos artísticos más importantes que Carpio llevó a cabo durante sus años como embajador en Roma. Especialmente interesante para nosotros es el apartado titulado "Li Sette colli overo il disegno", dedicado a alabar la colección de dibujos de Carpio y a describir algunas de sus piezas ${ }^{35}$.

Según la narración de Baldini (ver apéndice documental), en la parte superior del dibujo una diosa sentada sobre una nube sostenía el retrato de Carpio. En la parte central, una Fama levantaba una corona de laurel con su mano derecha y una trompeta con la izquierda; mientras que un putto

31 CHeCA 1995: 60. Véase también CHECA, 1991: 21-28.

32 ACA caja 302-4, f. 156v: 'Un quadro, che rappresenta un Dissegno fatto in Carta turchina lapiz nero, e rosso, Lumeggiato di biacca, che dimostra un Ercole con la massa [maza], 1' Invidia, e una Dea di sopra con un scettro [cetro] in mano et un Ritratto, La fama in cima, e alcuni amoretti, di mano di Giacinto Brandi, di palmi 2 e 11/2 con suoi Regoletti indorati, cristallo davanti stimato in [60 reales]'. El dibujo fue registrado en el inventario dentro del apartado dedicado exclusivamente a las obras compradas por Carpio.

33 El dibujo forma parte del libro titulado La Gratitudine, regalado a Carpio por Sebastiano Baldini. BNE RES/252, Nápoles, 1684. Publicado por primera vez en Frutos 2005b. Para una estudio del dibujo véase LóPEz-FANJul DíEz DEL Corral, 2011: 193-194.

34 En Il tempio della fama Baldini reunió diversos sonetos sobre episodios emblemáticos de Carpio en Roma. BBM B97-V2-23, ff. 68-78. Citado por primera vez en Frutos 2005a: vol. 1, 1113.

35 “Li STTECOLli / OVERo / IL DISEGNO. // Li SETTE COLli / CIOE / SETTE SONETTI / sopra un Disegno / fatto dal signor / GIACINTO BRANDI / Pittore Insigne / e donato / All' Eccellentissimo Signor / dON / GASPARO / D'HARO Y GVZMAN / Marchese del Carpio / Ambasciadore Ordinario, e Straordinario / Per Sua Maestá Católica / in Roma / dichiarato / Viceré di Napoli.' // 'Illustrissimo Signore / Non è vano il mio pensiero se com=/posti li seguenti Sette Sonetti sopra il / nobilissimo Disegno fatto dal celeber=/rimo Pittor Sig. ${ }^{\mathrm{r}}$ Giacinto Brandi / io mi risolva di dedicarli a VS. Ill. ${ }^{\text {ma }}$ tanto parziale e di questo virtuoso sog=/getto, e di quanti Professori in tutte le arti / più famosi vanta la Città di Roma. E cosi grande la dilei / intelligenza non solo in qualunque / genere di Pittura, e di Scoltura, ma / in tutte le mecaniche più rare, che fon=/do sul merito delle sue Virtù l'hono=/re, e la protettione a questi miei com=/ponimenti. Si compiaccia ella di // qualificarli col gradirli, e ravvisi in essi la stima, che faccio del Sig. ${ }^{\mathrm{r}} \mathrm{Gia}=/$ cinto e la veneratione, che porto à / quel Principe, che posto nel mezzo / del Disegno si puo dir con verità=/ = In medio consistit Virtus =/ Con che le faccio riverenza / Roma 12 xmbre 1682.

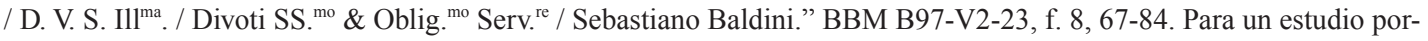
menorizado de esta obra véase LóPEz-FANJul DíEz DEL CORRAL, 2011: 190-196. 
sujetaba una cornucopia de la que medallas, monedas, cadenas de oro y joyas caían sobre pinceles, compases, cinceles y libros. En la parte inferior de la composición, Hércules con la maza pisaba al Vicio. Ateniéndonos a las explicaciones del poeta, todas las alegorías representadas aludían a las 'virtudes de Su Excelencia's6.

El primer grupo de objetos simbolizaba el éxito económico y político que se esperaba del virreinato de Carpio. El segundo aludía al coleccionismo de las artes por las que el Marqués era ya famoso. Y el tercero era una transposición de Carpio como nuevo Hércules. Como veremos más adelante, el Marqués fue numerosas veces comparado con héroes clásicos e históricos, pero especialmente recurrente fue su identificación con la figura de Hércules. Ejemplo de ello es el texto Il Regno festeggiante, publicado en 1683 con ocasión de la llegada de Carpio a Nápoles, donde el Marqués es identificado hasta dos veces con el héroe mitológico ${ }^{37}$.

Los elementos iconográficos ideados por Brandi fueron utilizados en los años posteriores de cuatro formas diferentes en diversos retratos oficiales de Carpio como virrey ${ }^{38}$. El más conocido y reproducido es el retrato ideado por Philip Schor y Giuseppe Pinacci (grabado por Jacques Blondeau en 1682 y 1683), que sigue la descripción de Baldini del dibujo de Brandi casi al pie de la letra (fig. 2) ) $^{39}$. En esta estampa, enmarcada por la corona-guirnalda de laurel, el retrato de Carpio domina la composición sostenido por el putto y la Fama, que hace sonar una trompeta de la que pende el escudo del Marqués ${ }^{40}$. En la parte superior aparece una extensa serie de trofeos militares clásicos que sustituirían a la figura de Hércules en la identificación del Marqués como héroe. Bajo el retrato se sitúan los elementos descritos por Baldini como símbolos del éxito político y artístico de Carpio junto con otros que ilustran la amplitud de sus colecciones ${ }^{41}$.

Relacionados con esta estampa se conservan dos dibujos. El primero es un apunte a pluma sin el retrato de Carpio y atribuido a Schor por G. Fusconi ${ }^{42}$. El segundo es uno de los dibujos prepara-

36 'La Nobiltà sedente in una nuvola, che additava col police destro il Ritratto di sua Eccellenza posto nel mezzo. La Fama volante per aria, che teneva colla destra una Corona, e colla sinistra una Tromba. Un Fanciullo alato, che versava da una cornucopia Medaglie, Monete, Catene d'Oro, e Gioie' sopra Pennelli, Scalpelli, compassi, e Libri, dinotando con simili strumenti le Arti Liberali. Un Ercole con la Clava che calpestava co' i piedi il Vitio circondato da Serpenti tutti geroglifici allusivi alle Virtù di sua Eccellenza'. '[...] tra le alter Figure si vede la Fama con una Corona di Alloro in mano.' BBM B97-V2-23, ff. 69-72.

${ }^{37}$ Biblioteca Casanatense (de ahora en adelante BC), Roma. Sig. Vol.misc.1127.5. Sonetos correspondientes a las regiones de Abruzzo y Toscana. Otro volumen conservado en la Biblioteca Nationale Centrale Emanuele III di Napoli (de ahora en adelante BNN) fue dado a conocer por primera vez en ZAMPINO, 1997: 235-236.

${ }^{38}$ F. Moreno ha estudiado como en las imágenes de los "gobernantes virtuosos" se tiende a unificar el código de representación para transmitir un mismo concepto a través de numerosas imágenes, subrayando los aciertos conseguidos y las esperanzas depositadas en ellos. MORENO, 1985: 17-26.

${ }^{39}$ Existen dos versiones casi idénticas de esta estampa. La primera está fechada en 1682, cuando Carpio todavía estaba en Roma: Roma, Istituto Nazionale per la Grafica FC. 117775. Aguafuerte, 413 x $280 \mathrm{~mm}$. Esta estampa está dedicada a la Princesa de Paliano, Carpio aparece sin peluquín y se acompaña de una larga dedicatoria firmada por Pinacci. La traducción al italiano de esta dedicatoria (Archivio di Stato, Roma: Cartari 88 ff. 270-272) fue repartida poco después y transcrita por primera vez en Fusconi, 2008. La segunda estampa está fechada en 1683, cuando Carpio ya estaba en Nápoles: BNE IH-4229-1. Aguafuerte, 461 x 281 mm. BARCIA, 1901: 864-1. La estampa de la BNE debió de ser realizada sobre una hoja del cuaderno de trabajo de Blondeau, ya que en su verso pueden apreciarse el doblez central de las páginas y los apuntes a sanguina para la preparación de una obra diferente.

${ }^{40}$ Baldini no describe el retrato de Carpio dibujado por Brandi.

${ }^{41}$ Un busto antiguo (colección de escultura), un medallón (colección de medallas), diferentes instrumentos matemáticos y dos esferas armilares (conocimientos en geografía), pentagramas e instrumentos musicales (ilustradores de sus logros como mecenas de la música), libros (su biblioteca), una paleta y diversos pinceles (colección de pintura), un reloj (colección de relojes), y tres álbumes de dibujos (colección de dibujos).

${ }^{42}$ Fusconi, 2010: 1-11. Agradezco profundamente a la Dra. Fusconi que me permitiese leer el artículo antes de su publicación.

Arch. esp. arte, LXXXVI, 344, octUBRE-DICIEMBRE 2013, 291-310, ISSN: 0004-0428 


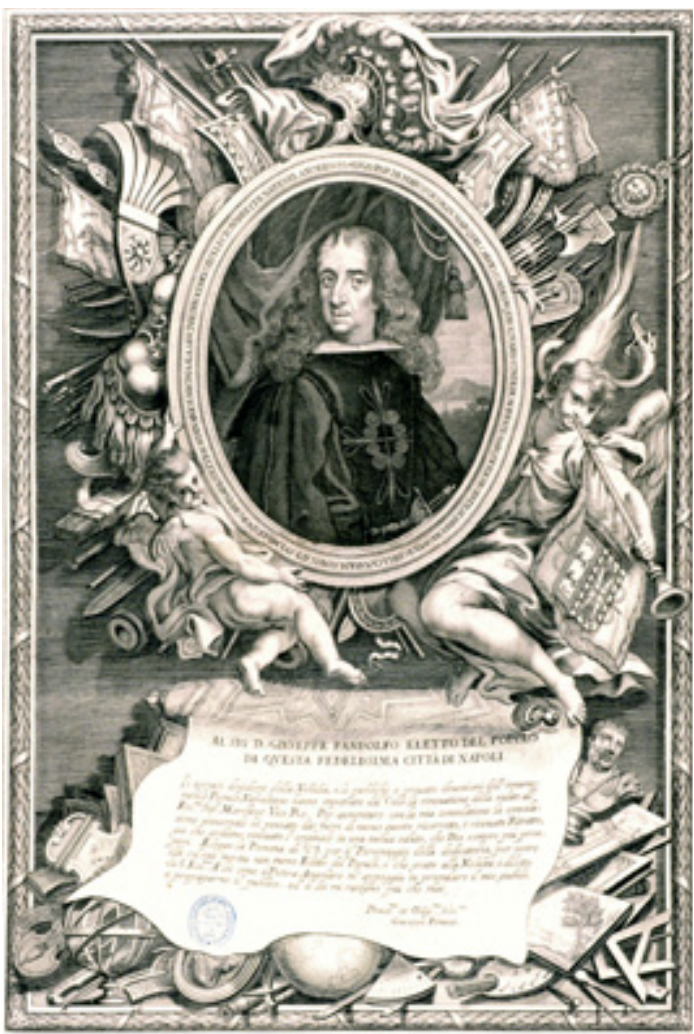

Fig. 2. Retrato de don Gaspar de Haro y Guzmán 1683 Philip Schor, Giuseppe Pinacci y Jacques Blondeau. Aguafuerte. Biblioteca Nacional de España.

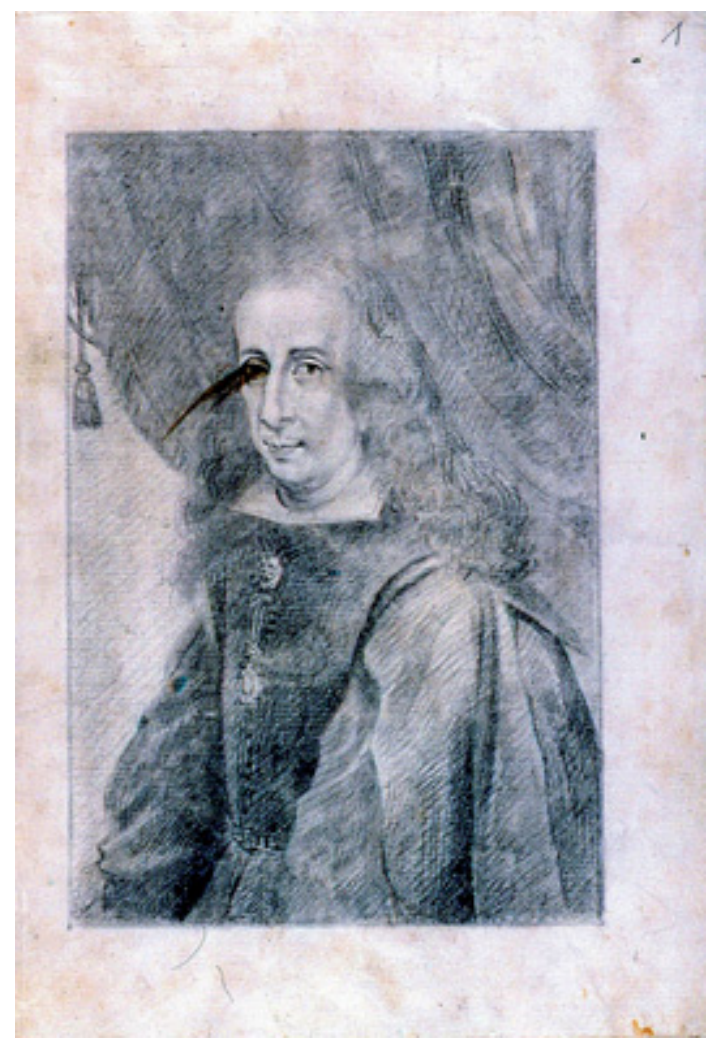

Fig. 3. Retrato de don Gaspar de Haro y Guzmán c. 1683 Anónimo. Carboncillo y tinta negra. Biblioteca Nacional de España.

torios para el retrato, conservado por Juan Vélez de León secretario de Carpio, realizado a carboncillo y con retoques a pluma y tinta negra (fig. 3 ) $^{43}$. Según las crónicas, el retrato de la estampa seguía un lienzo pintado por Pinacci ${ }^{44}$. Sin embargo, la comparación entre la estampa y el dibujo guardado por Vélez de León parece indicar que se están siguiendo dos modelos diferentes. Quizás, sugerimos, adaptando el rostro retratado por Pinacci al modelo general dado por el dibujo perdido de Brandi.

Producto de esta adaptación podría ser la torsión antinatural de la cabeza del Marqués en la estampa, mientras que en el dibujo ésta se sitúa correctamente. Esta incómoda posición, hemos podido comprobar, se consigue si invertimos la parte inferior del dibujo ${ }^{45}$. Entonces, el cuerpo del Marqués queda exactamente en la misma posición que en la estampa y su cabeza mirando hacia el lado contrario. La posición correcta del dibujo (aunque invertida hacia la derecha) y la ausencia de la espada serán también las pautas que siga la fig. 6, que estudiamos más adelante. Además, el adorno de flecos a lo largo del borde del cortinaje, que aparece en el dibujo y no en la estampa, volverá a ser utilizado en la fig. 7.

${ }^{43}$ BNE ms. 7526. Carboncillo y tinta negra. 277 x $198 \mathrm{~mm}$. CHECA, 2003: 33.

${ }^{44}$ Inghirami, 1844: vol. 14, 115: "Pinacci Giuseppe [...] Passò poi a Roma, dove fu provveduto di onorevoli impieghi: addestrata la mano a fare ritratti, dipinse tanto al naturale quello del marchese del Carpio che meritò di servire per le stampe".

${ }^{45}$ Comprobación realizada mediante el programa de ordenador photoshop. 


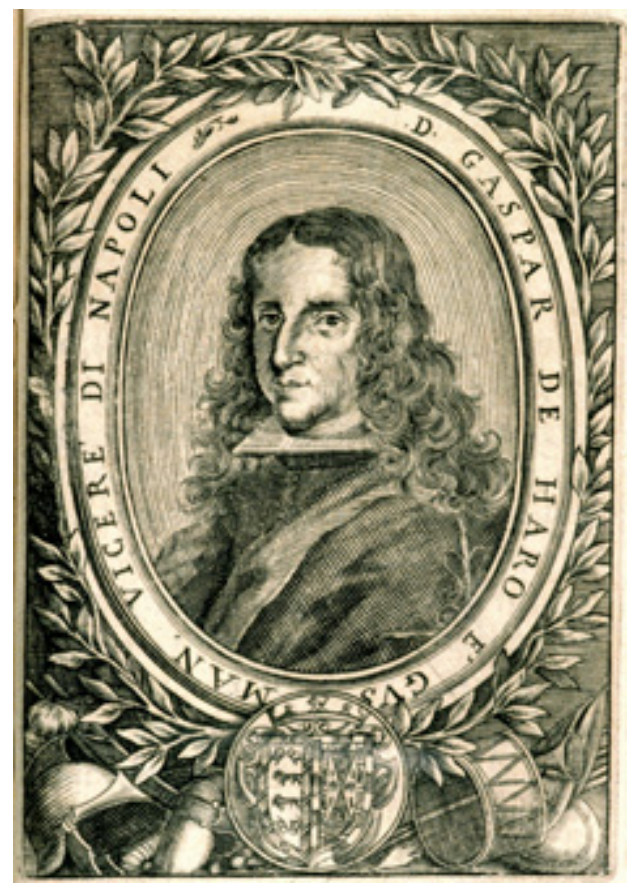

Fig. 4. Retrato de don Gaspar de Haro y Guzmán c. 1688 Antonio Bulifon. Aguafuerte. Biblioteca Nacional de España.

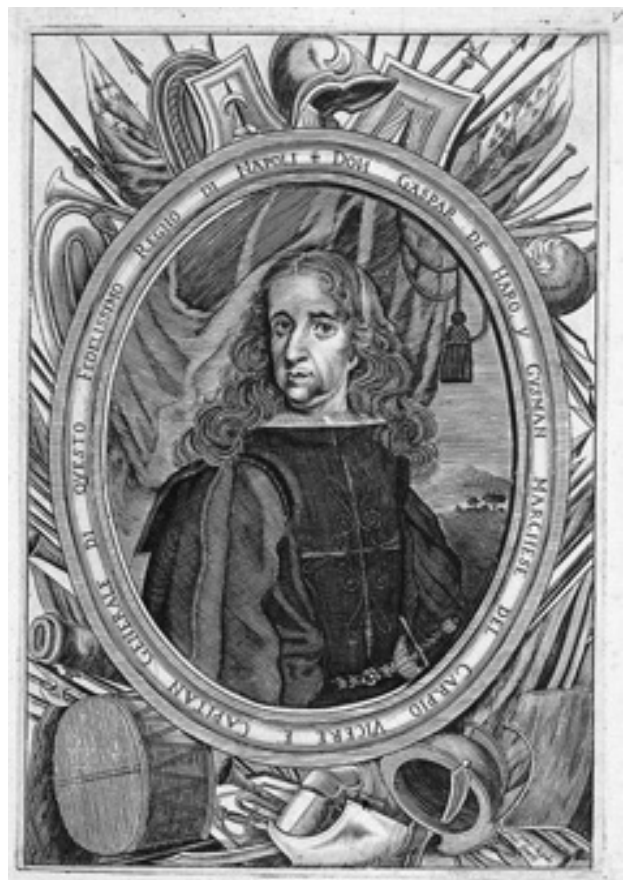

Fig. 5. Retrato de don Gaspar de Haro y Guzmán c. 1687 Francisco de Grado. Aguafuerte. Biblioteca Nacional de España.

Aparte de esta conocida estampa, otras dos forman parte de este grupo de retratos basados en el dibujo de Brandi. En ellos, sus autores Antonio Bulifon y Francisco de Grado redujeron los elementos alegóricos exclusivamente a aquellos que aludían a la figura de Carpio como héroe. La elección de Bulifon está basada en el propio texto del libro al que acompaña, Compendio delle vite dei re di $\mathrm{Na}$ poli: con li ritratti al naturale fechado en 1688, y que recuerda el gran triunfo del Marqués como pacificador del reino (fig. 4) ${ }^{46}$. El retrato de Carpio ocupa casi la totalidad de la composición, rodeado por la corona de laurel y acompañado en la parte inferior por su escudo y los trofeos clásicos. En este caso el cortinaje del fondo ha desaparecido y el diseño del retrato ha sido reducido al máximo.

La estampa de Grado ilustra el libro de Domenico Colonna Compendio de servitii ottenuti nel felicissimo governo dell' eccellentissimo signor marchese del Carpio, publicado en Nápoles en 1687 (fig. 5) ${ }^{47}$. Al contrario que la obra de Bulifon, el artista respeta casi totalmente el retrato de

${ }^{46}$ BNE ER/651 (211) BuLIFon, 1688: 211, 212-214: 'Quindi non passò guari, che mutò faccia il Regno, quasi doppo lungo ingombramento un placido sereno provando; fù purgato da ladroni, e scherani, che le campagne tutte con ruberie, ed [p. 213] occisioni infestando, i cammini a passatori, e viandali mal sicuri rendevano. Erano negli Abbruzzi gli sbanditi sì, e talmente avanzati, per la fortezza de'luoghi montuosi, ove ricoveravano, che non solamente spogliavano i viandanti, e imponevan taglie, ma di vantaggio, uscendo a guisa d'orte, i villaggi d'intorno correvano, e le Terre, e le ben guernite Città, con crudeltà, e morti malmenando saccheggiavano; il valoroso Signore per impor compenso a tanti danni, vi spedì ben fornite schiere di Soldati, che doppo avervi molta fatica, e contrasto durato, gli sterminarono, ed acciocchè per innanzi non potessero fra quelle asprezze annidarsi, sè alzarvi assai guerniti fortini. Impresa da altri Vicerè per addietro tentava, mà non già per la malagevolezza dell'opera ridotta a capo.' Aguafuerte.

${ }^{47} \mathrm{BNE}$ IH/4229-2. Aguafuerte. 161 x $234 \mathrm{~mm}$. 
la fig. 2, aunque la corona de laurel ha desaparecido y los triunfos han pasado a ocupar todo el fondo de la composición.

En una cuarta estampa, también firmada por Grado, la decoración ha sido reducida drásticamente a aquellos elementos que en el dibujo de Brandi aludían a los logros políticos de Carpio (fig. 6) ${ }^{48}$. Fechada en 1683, podemos entender que la obra seguramente conmemoraba los mayores éxitos del

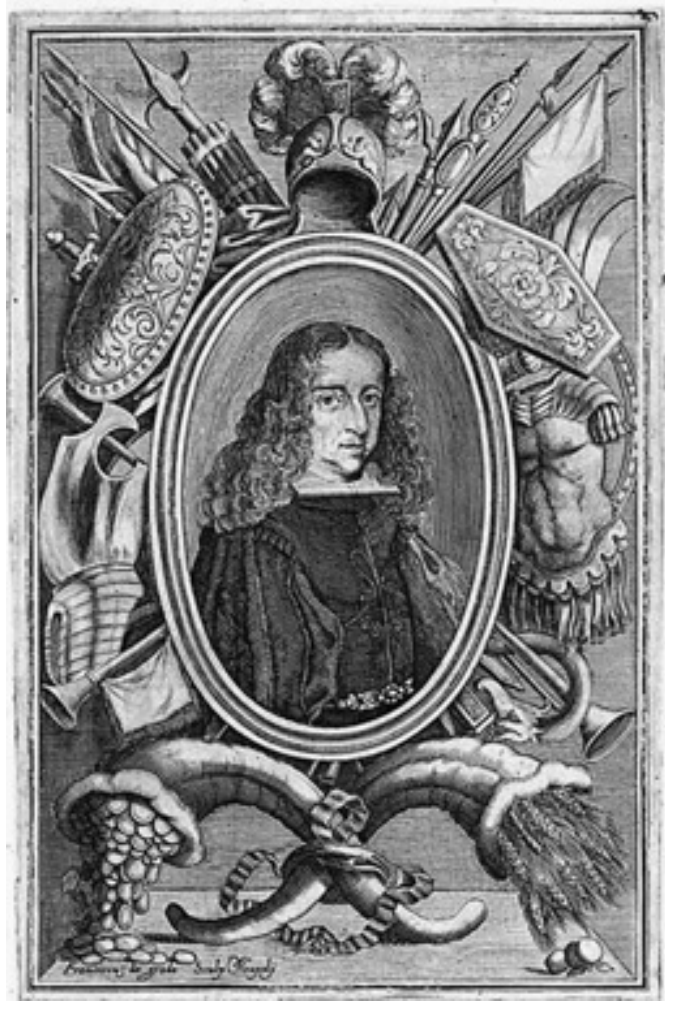

Fig. 6. Retrato de don Gaspar de Haro y Guzmán 1683 Francisco de Grado. Aguafuerte. Biblioteca Nacional de España. primer año del Marqués como virrey: la pacificación del territorio y la prosperidad económica ${ }^{49}$. En ella, el retrato de Carpio se ha reducido de tamaño, el cortinaje ha desaparecido, el espacio restante está adornado con los trofeos que hemos visto en las dos obras anteriores y se han añadido las cornucopias de las que caen monedas y espigas de trigo que describía Baldini del dibujo de Brandi.

Finalmente, dos últimos retratos podrían estar relacionados de manera indirecta con el dibujo de Brandi. Como Baldini menciona en sus versos, el artista realizó una pintura tras terminar el dibujo, un 'retrato [de cuerpo] entero de Su Excelencia" 50 . Esta composición es quizás la grabada por Arnoldo van Westerhout justo antes de que Carpio dejara Roma camino de Nápoles en una estampa a mezzo tinta que claramente está copiando una pintura hasta ahora desconocida y no descrita en los inventarios (fig. 7) ${ }^{51}$. En este retrato, Carpio está representado como Capitán General de Nápoles, vestido con armadura y empuñando el bastón de mando. La misma imagen fue reinterpretada un año después, en 1683, mirando en esta ocasión hacia la izquierda, añadiendo los trofeos alrededor del retrato y las monedas y espigas al fondo de la composición. Éstas están colocadas sobre los platos de una balanza en referencia a la estabilidad económica que Carpio consiguió en su primer año de virreinato gracias a las reformas de la moneda que llevó a cabo (fig. 8$)^{52}$.

${ }^{48}$ BNE IH/4229-3, firmado por Francisco de Grado. Aguafuerte. 181 x 118 mm.

49 Sobre los años de Carpio en Nápoles véase: PAz, 1903: 247-259 y 395-406; GHelli, 1933: vol. 1: 58, 80-318 y vol. 3: 59, 257-282; NiCOLINI, 1934: 263-291, 339-340; GALASSO, 1982: vol. 1, 267-297.

50 'Signor giacinto BRAndi Pittore Illustre che lasciando di terminare il Disegno si contenti di fare in Ritratto intiero di Sua Eccellenza per Consolatione di tutta la Città di Roma’. BBM B97-V2-23, f. 75.

${ }^{51}$ BNE IH/4229-4, firmado por Arnoldo van Westerhout. Manera negra (mezzo tinta). 417 x 312 mm. BARCIA, 1901: 392, no 864-3. CACCIOTTI, 1994: 134. Inscripción: "Illustrissimo Heroi, ac Domino Excellentissimo / D. GASPARI DE HARO ET GVSMAn / Marcchioni de Carpio, duci de Montoso Comiti duci de Oliuares \&. / Hispaniarum Magnate nato, \& Indiarum Magna Cancellario, Ex Consilis belliet Status pro CAROLO II. / Monarca semper, x ubique Católico as ss.d. INNOCENTIVM XI. Legato Ordinario \& Extraordinario / nunc denum Regni Neapolitani pro meritis pro, Regi”.

${ }^{52}$ BNE ER-574. firmado por N. Pesche y fechado en 1683. La misma estampa se conserva en BNN Ms. XV, G 24, c. 69v. BARCiA, 1901: 392, nº 864-4. PisANi, 1997: 61. Aguafuerte. 122 x 75 mm. Sobre las reformas económicas llevadas a cabo por Carpio en Nápoles, véase: Nicolini, 1934: 263-291, 339-340. Galasso, 1982: 267-297 (vol. I). Galasso, 2007; 681-709 (vol. 3). 


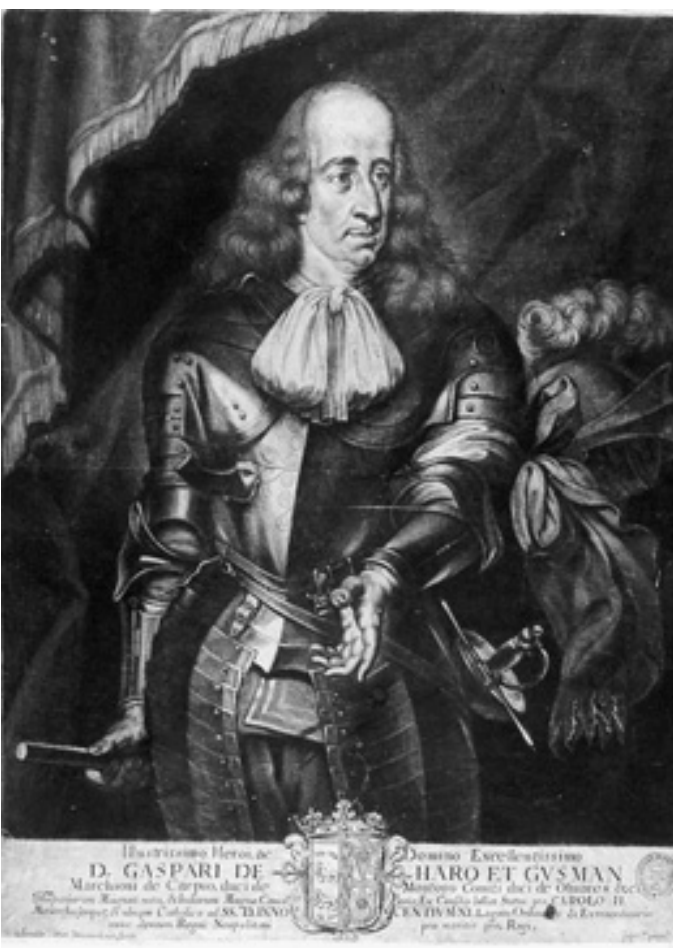

Fig. 7. Retrato de don Gaspar de Haro y Guzmán c. 1682 Arnoldo van Westerhout. Manera negra. Biblioteca Nacional de España.

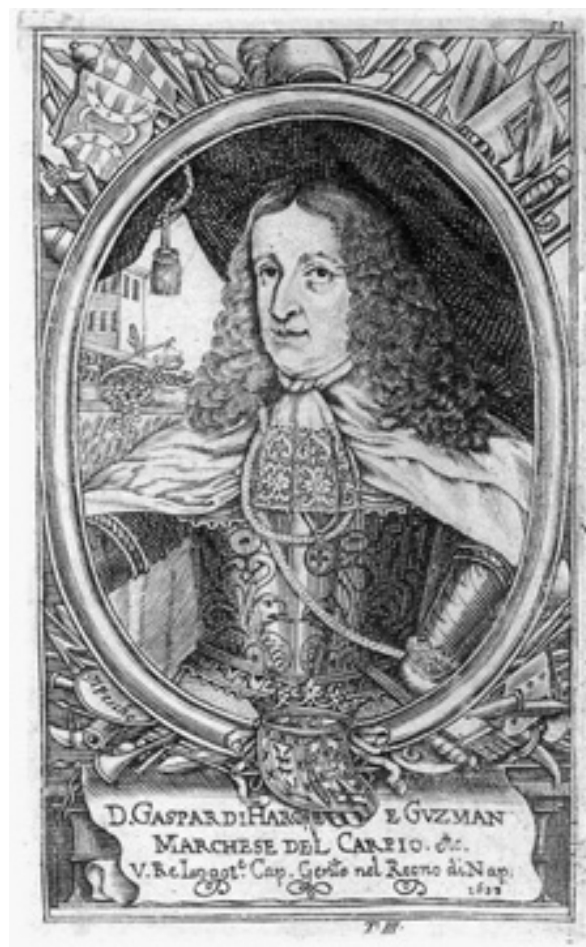

Fig. 8. Retrato de don Gaspar de Haro y Guzmán 1683 N. Pesche. Aguafuerte. Biblioteca Nacional de España.

Tras este grupo de retratos herederos del dibujo de Brandi, un tercer conjunto está compuesto por tres estampas y un dibujo realizados durante el virreinato. Éstos se apartan significativamente de las pautas de los anteriores retratos y se enmarcan dentro del género del emblema. En la España barroca los libros de emblemas tuvieron gran éxito. Este tipo de representación se entendía como un poema figurativo, una suerte de memoria visual que sintetizaba las aspiraciones y valores promovidos por el poder ${ }^{53}$. Por ello, este género fue especialmente popular entre la nobleza y el propio Carpio coleccionó dibujos-emblemas e incluso los utilizó en el diseño de los frontispicios para sus álbumes de dibujo, como veremos más adelante ${ }^{54}$.

La primera obra que compone este tercer grupo es un retrato en el que Carpio está representado de manera muy similar al dibujo de la fig. 4, pero sin ningún atributo a excepción de la leyenda 'imposible es posible ${ }^{55}$. Ésta podría interpretarse como una referencia al éxito económico y político que el Marqués logró en sus primeros años napolitanos, que ya hemos referido en retratos anteriores.

53 Sobre emblemas y poder en España véase: Maravall, 1972. Moreno, 1985. Portús, 1999. Zafra, Azanza, 2000. Mínguez, 2001: 109-126; BouZA, 2008: 41-64.

${ }^{54}$ Véase López-Fanjul, 2010 y López-Fanjul Díez del Corral, 2011: 146-151, donde profundizo en la naturaleza de los frontispicios como emblemas. El uso de los emblemas en la colección de dibujos Carpio fue tratado en la conferencia Identities and Instrospections on Paper: Emblems and the Marqués del Carpio's Collection of Drawings (1629-1687), 4 de Octubre de 2010, Wallace Collection- Londres.

${ }_{55}$ Estampa publicada por ANSELMI, 2004: 563-595. El artículo de Anselmi no menciona que el escudo que acompaña al de Carpio pertenece a la familia Zúñiga. Desconocemos el porqué de este escudo en la composición ya que ni Carpio ni sus 


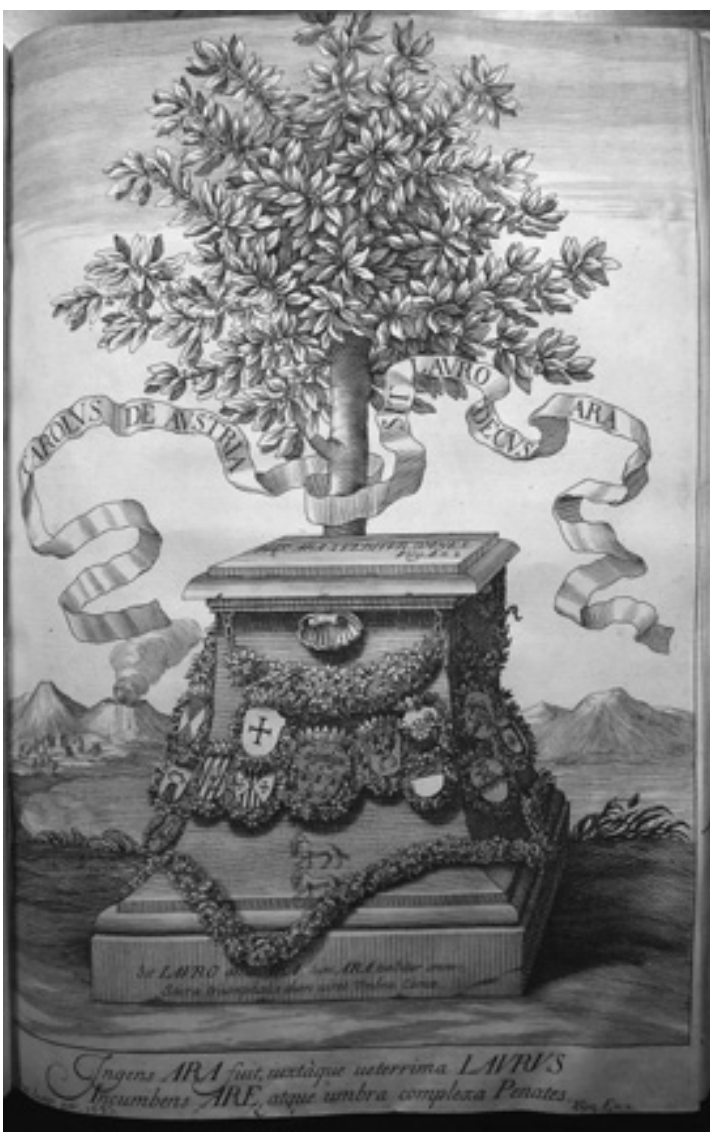

Fig. 9. Alegoría de don Gaspar de Haro y Guzmán 1683 Anónimo. Aguafuerte. Biblioteca Casanatense, Roma.

La segunda obra de este tercer grupo la consideramos en este artículo como retrato, a pesar de que formalmente no contenga ninguno (fig. 9). Se trata de la primera página y única ilustración del libro Regno festeggiante, fechado en $1683^{56}$. Iconográficamente está basada en el emblema 'virtuti fortuna comes' de Th. de Bry, realizado para la obra Romanae urbis topogrephia de J. Boissard, aunque su lectura depende de la interpretación de un pasaje de la Eneida de Virgilio ${ }^{57}$.

En este caso Carpio ha sido alegóricamente retratado como el altar que protege al virreinato napolitano. Éste está situado frente a la bahía de Nápoles y en él están grabados los lobos del escudo de los Haro. A su alrededor cuelgan los escudos de las ciudades bajo mandato español y está acompañado de un laurel.

En la parte superior del podium y en la inferior de la imagen se pueden leer dos citas del Libro 2 de la Eneida: "H[A]EC ARA TUEBITUR OMNES" (este altar nos protegerá a todos)" e "Ingens ara fuit, juxtaque veterrima laurus, / Incumbens arae atque umbra complexa Penates (hubo un altar ingente, y junto, un vetustísimo laurel / al ara inclinado, y abrazando a los penates con su sombra)". Las frases pertenecen al pasaje en el que el rey Príamo se ciñe las armas en un último intento de salvar Troya mientras es exhortado por su mujer Hécuba a dejar la lucha y a refugiarse junto a un altar al lado del cual crece un laure ${ }^{58}$.

Otras dos frases sitúan el pasaje clásico en la historia moderna napolitana. La primera, escrita en una leyenda que se enrosca alrededor del tronco del laurel, es un homenaje explícito a Carlos II e implícito a Carpio: “CAROLUS DE AUSTRIA SIT LAURO DECUS ARA (sea Carlos de Austria gloria [o adorno] para el laurel [o triunfo] en el altar)"s9. En este caso, el término latino "laurel" también podría traducirse como "triunfo", por lo que la frase

mujeres pertenecían a la familia Zúñiga. Quizás pudiera estar en relación con su hija Catalina, quien recibiría el título de Marquesa de Monterrey y los apellidos de Fonseca y Zúñiga como única heredera de su tía política Inés de Fonseca y Zúñiga.

${ }^{56}$ BC Roma: vol.misc.1127.5, Il Regno festeggiante, 1683. Aguafuerte.

${ }^{57}$ BoIsSARD, 1600: vol. 5, A I recto.

${ }^{58}$ Virgilio, 2006: libro II, versos 526-525: “Aquí, en torno a los altares, Hécuba y sus hijas en vano, / como en negra tempestad las palomas precipites, juntas / y abrazando las imágenes de los dioses, sentábanse; / mas cuando vio, tomadas las armas juveniles, al mismo Príamo, 'Qué mente tan desdichada, misérrimo cónyuge, / te impulsó a ceñirte estas armas? ¿O a donde corres?', le dijo. / 'No de un tal auxilio ni de estos defensores requiere / el tiempo. No aunque mi mismo Héctor estuviera presente. / Acá, al fin, retírate; nos cuidará a todos esta ara, o a la vez moriremos."

${ }^{59}$ Agradezco profundamente la ayuda prestada por Pablo Pérez d’Ors en la traducción de esta cita. 
podría interpretarse como una loa al Rey o, siguiendo el juego de palabras, como una alusión al triunfo personal de Carpio, cuyo ejército pacificó el virreinato a pesar de la oposición de Carlos II al enfrentamiento militar ${ }^{60}$. La segunda frase, inscrita en la base del altar, está construida combinando la anterior con las citas de Virgilio y manifiesta abiertamente la confianza del pueblo napolitano en la protección que recibirá del Marqués a lo largo de todo su mandato: "Sit LAVRO decus ARA; haec ARA tuebitur omnes; Sacra triumphalis dum viret umbra comae (Sea el altar triunfal gloria para el laurel sagrado; este altar nos protegerá a todos mientras esté fresca la sombra de sus hojas)" ${ }^{\prime \prime 1}$.

La tercera obra de este último grupo tampoco retrata formalmente a Carpio sino que de nuevo utiliza el emblema como sutil herramienta alegórica. Se trata del frontispicio del álbum de dibujos conservado en la Society of Antiquaries of London, cuya importancia mereció una entrada individual en el inventario de la almoneda madrileña del Marqués y un lugar de honor en los primeros estudios sobre coleccionismo (fig. 10) ${ }^{62}$.

El dibujo, atribuido a Philip Schor por G. Fusconi, no está fechado pero gracias a la leyenda que le acompaña sabemos que fue realizado a partir de 1682, tras ser nombrado Carpio virrey de Nápoles ${ }^{63}$. Éste representa una mujer sentada, tocada con un casco y sosteniendo la representación de una ciudad con su mano izquierda y una plataforma con la derecha, de la que cae una cascada de agua al mar. El tema ha sido relacionado por G. Fusconi con una alegoría de Roma y por E. Harris con la representación de Alejandro Magno como Monte Athos en el célebre dibujo

${ }^{60}$ Carlos II temía que un enfrentamiento armado provocara una revolución de los napolitanos. Para más información sobre el conflicto véase: Ghelli, 1933-1934. Paz, 1903. Sobre la política militar de Carpio en Nápoles: Nicolini, 1934: 263-291 y 339-340. Galasso, 1982: vol. I, 267-297; 2007: vol. 3, 681-709.

${ }^{61}$ Agradezco profundamente la ayuda prestada por Pablo Pérez d'Ors en la traducción de esta cita.

${ }^{62}$ Society of Antiquaries of London: SAL Ms 879. Archivo histórico de protocolos, Madrid (AHPM) protocolo 9819 , f. 899: "un tomo de diferentes dibujos y estampas". Pluma, tinta gris y aguada. 420 x $280 \mathrm{~mm}$. Álbum citado por primera vez en HASKell, 1971: 190.

${ }^{63}$ FusCONI, 1985: 172-173.

'DISEGNI / D' Idoli, Statue, Filosofi, Busti, Vrne piccolo, Bassi Rilieui, / Medaglie, Inscrittioni, Vasi di Marmi, e Porfidi, Fontane di Marmi, Ala=/bastri, e Metalli antichi e moderni; Quali Comprò In ROMA / L' Ecc. ${ }^{\text {mo }}$ Signore DON

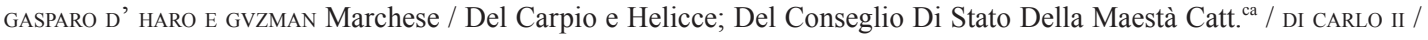
Suo Ambasciatore Ordinario, et Extraordinario Alla Santita di Nro Signore/ PAPA INNOCENZO XI / E nel 1682 Eletto Vice Re e Capitan Generale Del REGNO DI NAPOL [sic]'. 
de Pietro da Cortona ${ }^{64}$. Sin embargo, su interpretación es mucho más compleja y está directamente relacionada con la personalidad del Marqués.

La representación de Cortona tenía un significado concreto para Carpio y fue elegido con una clara intención. Ésta fue originalmente diseñada como frontispicio de la tesis del español Cristóbal Lozano, leída en la Sapienza en 1666, y cuyo grabado se hizo rápidamente famoso ${ }^{65}$.

Como hemos visto en el segundo grupo de obras analizado, el Marqués fue comparado en numerosas ocasiones con héroes clásicos e históricos. Además de Hércules y de Ulises, como veremos más adelante, uno de los héroes más recurrentes fue Alejandro Magno, quien había sido utilizado por Baltasar Castiglione como modelo ideal de gobernante al combinar el ejercicio del poder con la difusión cultural ${ }^{66}$. Este símil aparecerá de nuevo, por ejemplo, en la arquitectura efímera diseñada por Teresa del Pò para el carnaval napolitano de 1687, en una loa de Juan Vélez de León ${ }^{6}$; en el poema Il Tempio della Fama de Sebastiano Baldini - quien equipara el corazón de Carpio al de Alejandro -, y en el recibimiento del Marqués a su llegada a Nápoles, donde fue bienvenido como el "nuevo Alejandro"

A pesar de las similitudes formales con la obra de Cortona, nuestro dibujo también incluye importantes e intencionados cambios. En primer lugar, la ciudad que sostiene la alegoría no es la representación de una ciudad ideal sino de la propia Roma, en la que pueden reconocerse elementos como la cúpula de San Pedro y la columna trajana. En segundo lugar, las piernas y pies de la alegoría no se sitúan juntos sino formando el perfil de la bahía de Nápoles. Y, por último, mientras que el Alejandro de Cortona está rodeado por agua, la montaña del dibujo carpiano forma parte de una cordillera, posiblemente los Apeninos. La equiparación alegórica del Marqués con una cordillera es un elemento de glorificación que también se utiliza en 1683 en la obra Il Regno festeggiante. En ella, el Marqués es identificado con los Pirineos, símil de su propia fuerza y poder político ${ }^{69}$.

Por todo esto, proponemos la lectura de este dibujo como una representación alegórica y emblemática de Carpio, en la que su poder es representado sólido como una montaña, protegiendo y proveyendo para sus súbditos en las dos únicas ciudades en las que pudo ejercer su poder político, Roma y Nápoles.

La cuarta y última obra fue diseñada y grabada en 1683 para conmemorar el nombramiento de Carpio como nuevo virrey en Nápoles. Al igual que las dos anteriores, esta estampa no fue producto de un encargo oficial y su lectura debe ser por ello más sutil. En este caso, la estampa ilustra el texto del libro de Ponce de Soto Memorial de las tres Parténopes (fig. 11) ${ }^{70}$. Como veremos a continuación, se trata de un emblema directamente relacionado con el apellido Haro.

${ }^{64}$ El dibujo de Cortona fue grabado por François Spierre: British Museum 1860,0616.27. Representa al papa Alejandro VII y el Monte Athos esculpido con la imagen de Alejandro Magno. Está basado en una historia del emperador, según la cual su arquitecto Deinokrates transformó la montaña en una escultura de Alejandro. HarRIs, 1997. FusConi, $1985: 177$.

${ }^{65}$ La música para la defensa de la tesis fue compuesta por Nicolò Stamegna (JoHn, 2004: 22, nota 39). Lamentablemente éstos son los únicos datos que se conocen sobre Lozano. Sobre Cortona como diseñador de frontispicios para tesis véase: RicE, 1999: 189-200.

${ }^{66}$ CAstiglione, 1528.

${ }^{67}$ Visceglia, 2008: 207-212; BNE Ms 2100, ff. 136-138v, citado por LóPEZ TorRiJos, 1991: 27-36.

Philip Schor y Bergamo da Gorle. Flota de Carnaval. Reproducido en Wallace (Bartsch), 1990: nº 57.

68 'la finezza di questo Principe, che serbando nel petto un Anima di Cesare, e un Cuore d'Alessandro ha saputo captivarsi gl'animi di tutta la Nobiltà Romana.' 25 de Febrero de 1682. BBM B97-V2-23: 19. 'Spera la Città Fedelissima di Napoli, che il suo Destriero non farà restio à farsi maneggiar da questo nuovo Alesandro; e che non solo acquisterà maggior fama, ma diverrà più generoso morsicato da suoi LUPI come notò l'Altovrando, per la retta Giustitia, che esercita.' Società Napolitana di Storia Patria (de ahora en adelante SNSP) Sig. II, inv. 23152, Pinto, 1683: 5.

69 '[sobre Carpio] ¡Alpi, Norte, Pirene! e chi declina / Tanto furor? s'un HARO il Circol faccia / (Virtù d'Incanto) il mal non s'avvicina.' BC vol.misc.1127.5, Il Regno festeggiante, 1683.

${ }^{70}$ SNSP D.07.E.39: Ponce de Soto, 1683. Aguafuerte. 
Carpio demostró durante toda su vida predilección por el apellido heredado de su padre Don Luis. Un acrónimo de éste fue el que utilizó para marcar sus libros, pinturas y álbumes de dibujos: DGH (por don Gaspar de Haro), acompañado por la corona del marquesado en la parte superior ${ }^{71}$. Es más, la cercanía ortográfica entre las palabras Haro y aro, llevaron a un fructífero juego de dobles significados que dejaron tanto ejemplos escritos como en la retratística emblemática, donde la forma redonda del apellido Haro se transformó en metafórico sinónimo de Carpio.

En la estampa que nos concierne el retrato del Marqués cuelga dentro de un aro que se sujeta por una arandela a un baldaquino ricamente decorado. Debajo le acompaña su escudo rodeado por una corona de laurel. En la parte inferior aparece la leyenda 'O CARPIO LICET'. $Y$ en la escena central tres alegorías femeninas se sientan sobre tres escalones, la última bañada por las aguas del mar y con cola de sirena. En su conjunto, la obra es claramente una oda a Carpio, subraya la esperanza que la ciudad de Nápoles tiene en el gobierno del Marqués y le retrata hasta en cuatro ocasiones.

Alabando a Carpio, todas las mujeres alzan su mano derecha hacia su retrato sujetando un escrito donde podemos leer 'Ex. ${ }^{\mathrm{mo}} \mathrm{S} .{ }^{\text {or }}{ }^{72}$. La

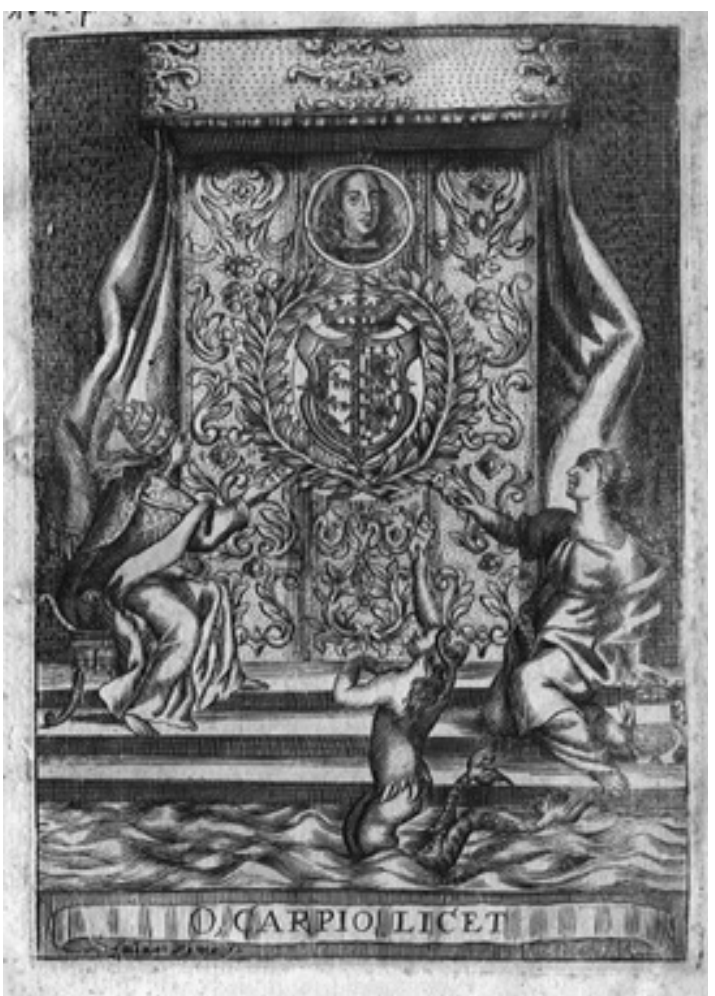

Fig. 11. Retrato de don Gaspar de Haro y Guzmán 1683 Anónimo. Aguafuerte. Società Napolitana di Storia Patria, Nápoles. primera, a nuestra izquierda, representa Roma tocada con la tiara Papal; ciudad donde el Marqués ejerció de embajador de España. La segunda, sosteniendo el escudo napolitano con su mano izquierda y tocada con una corona, simboliza el virreinato de Nápoles. Y la tercera alegoría alude a Parténope; una de las sirenas de Ulises que muriendo en las costas del golfo de Nápoles dio a la ciudad su primer nombre.

El retrato circular es una triple representación del Marqués. La primera y más obvia es la propia imagen de Carpio. En segundo lugar, la forma circular y la posición preeminente y elevada del aro aluden a la figura del Sol como metáfora de $\mathrm{Carpio}^{73}$. En el propio texto del libro al que acompaña la estampa el astro se convierte en sinónimo del Marqués, de quien dice que con sus "ylustre[s] rayos" protege "el estado de su Dominio"; esto es, las ciudades de Roma y Nápoles representadas en las alegorías femeninas. Por último, la perfección inherente a la figura circular del aro también es metáfora de Carpio como 'heroe incomprehensible, y cassi infinito ${ }^{74}$. Más concretamente, la

${ }^{71}$ La corona de marquesado alterna perlas y florones. Para una descripción detallada e ilustraciones de este tipo de coronas véase García CARRAFFA, 1919: 142-143.

72 Excelentísimo Señor.

${ }^{73}$ Como explica V. Mínguéz, la iconografía solar fue particularmente usada para representar a los monarcas españoles y a la monarquía hispánica. Mínguez, 2001: 109-126.

74 Ponce de Soto, 1683: 10v. 
figura geométrica es una transposición de Carpio como el héroe Ulises. A este símil alude implícitamente la imagen de la sirena Parténope y explícitamente otro texto de la época titulado La felicità de Partenope en el que Carpio es definido como "Ulises hispano"".

Por último, la misma metáfora de Carpio como héroe 'circular' aparece en la ' $\mathrm{O}$ ' inicial, más redonda y grande que las demás letras, de la leyenda 'O CARPIO LICET', que podríamos interpretar como abreviatura de Ovnis y de Orbis y leer como 'todo es lícito para Carpio" ${ }^{76}$.

\section{APÉNDICE DOCUMENTAL}

Sebastiano Baldini. Il Tempio della Fama. Rome, 1682, pp. 66-77. Biblioteca Bartolomeu March, Palma de Mallorca. Signatura B97-V2-23

"À chi Legge / Per intelligenza de'i seguenti sette sonet=/ti di deve sapere, che l'Eccellentissimo Sig. ${ }^{\mathrm{r}}$ / Don GASPARO de HARO y Guzman / Marchese del Carpio Ambasciadore or=/dinario e Straordinario della Maestà $\mathrm{Cat}=/$ tolica in Roma dichiarato ViceRè di $\mathrm{Na}=/$ poli, desiderando un Disegno dal Sig. ${ }^{\mathrm{r}}$ / Giacinto Brandi Pittore insigne, questi / delineo in un foglio / La Nobiltà sedente in una nuvola, che ad=/ditava col pollice destro il Ritratto di Sua / Eccellenza posto nel mezzo / La Fama volante per aria, che teneva colla / destra una Corona, e colla sinistra una Tromba. // Un Fanciullo alato, che versava da una Cornu=/copia Medaglie, Monete, Catene d'Oro e / Gioie sopra Penelli, Scalpelli, compassi / e Libri, dinotando con simili Strumenti / le Arti Liberali. / Un Ercole con la Clava che calpestava co' i / piedi il Vitio circondato da Serpenti tutti geroglifici allusivi alle

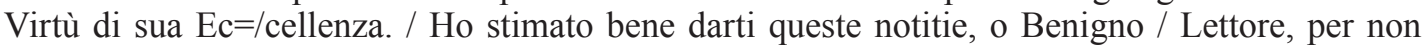
tediarti col ripetere in ogni so=/netto il medesimo sentimento, e vivi felice. // Qual sia il pensiero del Sig. ${ }^{\mathrm{r}}$ / GIACINTO BRANDI / Pittore Insigne / circa il Disegno / da presentarsi / á Sua Eccellenza. // SONETto Po. / Miro d'un Foglio folgorar nel seno / Sù nube d'or la Nobiltà Sedente, / Ch'addita quell' Eroe, per cui dolente / Lagrima il Tebro, e giubila il Miseno. / Dal Cornucopia di tesor ripieno / versar veggo un Fanciullo aureo Torrente: / Volar la Fama e Alcide al fie Serpente / Del Vitio calpestar l' Ira, e'l veleno. / Un dubio nel pensier chi mi decide. / Giacinto il Gran Pintor, dite, che brama / Che in tanti oggetti il suo lavor divide. / La Nobiltà per GASPARO s'acclama, / è GASPARO il Fanciul, GASPARO è Alcide, E per GaSPARO sol vola la Fama. // Al Signor GIACINTO BRANDI / che nel Disegno da lui fatto / non occorre di delinearvi il Ritratto / di Sua Eccellenza. // SONETTO II. / Oh con qual maestade in also siede / La Nobiltà da te, Giacinto, espressa: / E nel dipinto lin la Fama istressa / per coronar l'Eroe rivolge il piede. / In Hercol la Virtù viva si vede / De' i Vitij calpestar la Schiera oppressa: / E l'alato Fanciul lasciar non cessa / Ogn' Arte liberal di gioie' herede'. / Il regio Volto a contemplarvi arrivo / Del gran GASPARO D’HARO. Ahi qual dolore, / Quando il Tebro dovrà restarne privo. / Ma lo dipingi invan, saggio Pittore, / Che per veder l'EROE dipinto al vivo, / Basta di Roma sol vedere il Core. // Si rimprovera al Signor / GIACINTO BRANDI / Famosissimo Pittore / un difetto essentiale / trovato nel Disegno dato / nel quale tra le altre Figure / Si vede la Fama / con una Corona di Alloro in mano. // SONETTO III. / Io vidi hier, che a colorir t'accingi / La Nobiltà, Giacinto, entro un Disegno, / E che d'Ossequio, e di stupore in fegno / Ad accennar l'Ispano eroe l'astringi. / Poscia un alato Fanciullin tu fingi / Versar gioie su l'Arti, e u l' Ingegno / Ce calpesta col piede, anco dipingi. / Stringer la Fama oh come ben si scorge / Cõ la Destra

${ }^{75}$ BC vol. misc. 524.16. C. A. Sinibaldi, 1682: 11: 'Qui PARTENOPE bella / Con fatidici accenti, e arcane note / Trà varie forme ei lusingando assale. / A te propizia Stella, / Nobil mostro canoro, influir puote, / Le disse, alto destin, gloria immortale. / Porrà ben presto l'ale / Inver le Spume tue 1'ISPANO Ulisse, / Ch'a tue felicità Giove presisse.'

${ }^{76}$ Agradezco profundamente al Dr. Miguel Herrero de Jáuregui la ayuda prestada en la lectura de esta leyenda. 
d'Allori una Corona, / Ma chi dee coronarsi ah non s' accorge. / BRANDI, si grave error chi ti perdona / La Fama a EROE si grande una ne porge, / Quando a lui la Virtù mille ne Dona. // 'Si rivela / Al Sig. ${ }^{r}$ GIACINTO BRANDI / Pittore eccellente / un modo facilissimo / di fare il Disegno da presentarsi / à Sua Eccellenza / molto più espressivo / senza tante Figure Allegoriche // SONETTO Iv. / Risplender qui la Nobiltà rimiro, / Che addita altrui del grande Ibero il volto: / E mentre al piè d'Alcide il guardo io giro, / Veggo giacer tra gl' Angui il Vitio involto. / Scorgo, a stupor de l'Indo, e de l' Assiro, / Fanciul, che l' Urne d'or quivi ha rivolto: / Qui co la Tromba sua la Fama ammiro, / Chi un serto ha su la man di lauri avvolto. / È tua l' opera, o Giacinto; e chi mai vide / Più nobil Geroglifico, e più raro, Che in tante Cifre a le Virtudi arride. / Pur se in disegno vuoi formar più chiaro / Doni d'or, nobiltà, Fama, ed Alcide, Brandi, dipingi sol GASPARO D' HARO.' // Consiglio al Signor GIACINTO BRANDI / Pittore Illustre / che lasciando di terminare il Disegno / si contenti di fare un Ritratto intiero / di Sua Eccellenza / per Consolatione di tutta la Città di Roma // SONETTO v. ${ }^{\circ}$ / DAI, Giacinto, io lo sò spirto ài colori, / Sò, che le tele ad animare arrivi; / Ma giunger dei co' tuoi pennelli attivi / Di Roma afflitta a consolare i Cori. / A che quel Fanciullin le gemme, e gl' Ori / Versar su l' Arti liberal descrivi / A che la Nobiltà, la Fama avvivi, / Ed Ercol fai spirar ne' tuoi lavori. / Sù, di GASPARO D'HARO, EROE supremo, / L' Effigie intera ingrembo a un Lin disserra, / Se vuoi temprar di Roma il duolo estremo / Cesserà fra Theologi la Guerra, / Se lo dipingi tù, poiché vedremo, / Che in piú luoghi puó star l'Angelo in Terra. // Prima che Sua Eccellenza / parta da Roma per Napoli / Il Sig. ${ }^{r}$ GIACINTO BRANDI / Pittore incomparabile / gli presenta / il Sudetto Disegno. // SONETTO VI. / In alto qui la Nobiltà risiede, / La Fama stringe in mano una Corona, / Un Fanciullo à Virtù ricchezze dona, / Ercole il Vitio calpestar si vede. / Poi del dipinto lin nel mezzo siede / GASPAR, che in brevi di Roma abbandona, / Per girsene ove Flora, ove Pomona, / E Cerere, e Vertunno hanno la Sede. / Pur si ravvisa in lui tutto il disegno; / Fa del Fanciullo, e d' Ercole le prove, / Di Fama, e Nobiltà trapassa il Segno. / Partenope felice! Oh quante piove / In te fortune il Ciel. dentro il tuo Regno / GASPARO D' HARO aspetti, e viene un GIOve. // Si Splica la Cifra, / che contiene il medesimo Disegno / da presentarsi / a Sua Eccellenza / fatto dal Signor / GIACINTO BRANDI / Pittore Celeberrimo. // sonetTo viI. / La Nobiltà del tuo Pennel rimiro / E la Fama, che canta il tuo valore, / E fra Pittori un Hercole t'ammiro, Che calpesta col piè l'aspro livore. / Il Fanciul, che qual Creso, o Mida, o Ciro, / Sparge de' doni il meritato honore, / Addita altrui, che quante gioie usciro, / Solo devonsi tutte al suo sudore. / Ma l' Effigie di quei nel mezzo esposta, / Che in brevi giorni prenderà la Via / Ver la Città, che lungo il Mare è posta, / E qual co' gl' altri Oggetti ha Simetria. / Odi. Di questa Idea si ben disposta / GASPAR l' Ammirator degno è che sia."

\section{BIBLIOGRAFÍA}

Anselmi, Alexandra, "El marqués del Carpio y el barrio de la embajada de España en Roma (1677-1683)", en Álvarez-Ossorio, Antonio (ed.), La Monarquía de las Naciones. Patria, nación y naturaleza en la Monarquía de España, Madrid, 2004, pp. 563-595.

Anselmi, Alessandra, "Gaspar de Haro y Guzmán VII marchese del Carpio", en Visceglia, Maria Antonietta (ed.), Diplomazia e politica della Spagna a Roma. Figure di ambasciatori, Roma, 2008, pp. 187-253.

Barcia, Ángel, Catálogo de los retratos de los personajes españoles que se conservan en la Sección de Estampas y Bellas Artes de la Biblioteca Nacional, Madrid, 1901.

Bass, Laura, The Drama of the Portrait: Theater and Visual Culture in Early Modern Spain, Pennsylvania, 2008.

Bassegoda, Bonaventura, "Los retratos de don Luis Méndez de Haro", Locus Amoenus, 6, 2002/2003, pp. $305-326$.

Biblia de Jerusalén, Bilbao, 1976.

Brown, Jonathan, "Peut-on assez louer cet excellent ministre?: imágines del privado en Inglaterra, Francia y España", en Elliott, John. Brockliss, Laurence, El mundo de los validos, Madrid, 1999, pp. 321-338.

Burke, Marcus. Cherry, Peter, Collections of paintings in Madrid 1601-1755, Turín, 1997. 
Burke, Marcus, "Luis de Haro como ministro, mecenas y coleccionista de arte", en Brown, Jonathan. Elliott, John, La almoneda del siglo. Relaciones artísticas entre España y Gran Bretaña 1604-165, cat. exp., Museo del Prado, Madrid, 2002, pp. 87-106.

Bodart, Diane, 'Le portrait royal sous le dais. Polysémie d'un dispositif de representation dans l'Espagne et dans l'Italie du XVIIe siècle", en Colomer, José Luis (ed.), Arte y diplomacia de la monarquía hispánica en el siglo XVII, Madrid, 2003, pp. 89-114.

Boissard, Jean Jacques, Romanae urbis topographia, Frankfurt, 1600.

Bouza, Fernando, "Por no usarse. Sobre uso, circulación y mercado de imágenes políticas en la alta Edad Moderna”, en Palos, José Lluis (ed.), La Historia imaginada. Construcciones del pasado en la Edad Moderna, Madrid, 2008, pp. 41-64

Bouza, Fernando, "Cultura de élite, cultura de élites. Intencionalidad y estrategias culturales en la lucha política de la aristocracia altomoderna", en Soria, Enrique (et al), Las élites en la época moderna: la monarquía española, Madrid, 2009, 2 vols., vol. 1, pp. 29-46.

Bulifon, Antonio, Compendio delle vite dei re di Napoli: con li ritratti al naturale, Nápoles, 1688.

Cacciotti, Beatrice, "La collezione del VII Marchese del Carpio tra Roma e Madrid", Bollettino d'Arte (1994), 86-87, pp.133-196.

Cano de Gardoqui, José Luis, Tesoros y colecciones. Orígenes y evolución del coleccionismo artístico, Valladolid, 2001.

Castiglione, Baldassare, Il libro del Cortegiano, Venecia, 1528.

Checa, Fernando, "Alegorías elocuentes: la imagen del poder en la España del Barroco", en AAVV, Figuras e Imágenes del Barroco. Estudios sobre el barroco español y sobre la obra de Alonso Cano, Madrid, 1999, pp. 49-65.

Checa, Fernando, "Del gusto de las naciones", en Checa, Fernando, Cortes del Barroco. De Bernini y Velázquez a Luca Giordano, cat. exp., Patrimonio Nacional, Madrid, 2003, pp. 17-34.

Davies, David, "The Anatomy of Spanish Habsburg Portraiture”, en Bussmann, Klaus (ed.), 1648: War and Peace in Europe, Münster, 1998, pp. 69-79.

Dominici, Bernardo de, Vite dei Pittori, Scultori ed Architetti Napoletani, Adamant

Media Corporation, 2006, 4 vols.

Elliott, John, "Poder y propaganda en la España de Felipe IV", en Moya, Carlos (et al), Homenaje a José Antonio Maravall, Madrid, 1985, 2 vols., vol. 2, pp. 15-42.

Elliott, John, The Count-Duke of Olivares. The Statesman in an Age of Decline, Londres, 1986.

Fagiolo dell' Arco, Maurizio. Carandini, Silvia. L'effimero barocco, Roma 1977.

Fagiolo del' Arco, Maurizio, La festa a Roma 1500-1870, cat. exp., Palazzo Venecia, Roma, 1999.

Falomir, Miguel. "El retrato de Corte", en El retrato del Renacimiento, cat. exp., Madrid, 2008, pp. 109-123.

Farina, Viviana, "Collezionismo di disegni a Napoli nel Seicento: Le raccolte di grafica del vicerè VII marchese del Carpio, il ruolo di Padre Sebastiano Resta e un inventario inedito di disegni e stampe", en Colomer, José Luis, España y Nápoles. Coleccionismo y mecenazgo virreinales en el siglo XVII, Madrid, 2009, pp. 339-362.

Farina, Viviana, "La collezione del Viceré: Il Marchese del Carpio, padre Sebastiano Resta e la prima raccolta raginata di disegni napolitana”, en Solinas, Francesco. Schütze, Sebastian (eds.), Le Dessin napolitain: Actes du colloque international, École Normale Supérieure, 6-8 mars 2008, Roma, 2010, pp. 183-198.

Fernández Talaya, María Teresa, El Real Sitio de la Florida y La Moncloa: evolución histórica y artística de un lugar madrileño, Madrid, 1999.

Frutos, Leticia de, El VII marqués del Carpio (1629-1687): mecenas y coleccionista de las artes, tesis doctoral, Universidad Complutense Madrid, 2005a.

Frutos, Leticia de, "La Gratitudine, specchio della virtù: il dono di un lusuoso manuscrito ad un mecenate del XVII secolo", Rara volumina, 1, no. 2, 2005b, pp. 5-21.

Frutos, Leticia de, El Templo de la Fama. Alegoría del Marqués del Carpio, Madrid, 2010.

Fusconi, Giulia, "Philip Schor, gli Altieri e il Marchese del Carpio', Ein Regisseur des barocken Weltheaters: Johann Paul Schor und die internationale Sprache des Barock. Biblioteca Hertziana Max-Planck-Institut für Kunstgeshichte, Roma, 6-7 Octubre 2003, Munich, 2008.

Fusconi, Giulia, 'Il ‘buen gusto romano’ dei Viceré. La ricezione dell' effimero barocco a Napoli negli anni del Marchese del Carpio (1683-1687) e del Conte di Santisteban (1688-1696)", en Solinas, Francesco. 
Schütze, Sebastian (eds.). Le Dessin napolitain: Actes du colloque international, École Normale Supérieure, 6-8 mars 2008, Roma, 2010, pp. 1-11.

Fusconi, Giulia, “I disegni decorativi di J. P. Schor”, Bolletino d'Arte, 1985, nos. 33-34, pp. 159-179.

Galasso, Giuseppe, Napoli Spagnola dopo Masaniello, 2 vols., Florencia, 1982.

Galasso, Giuseppe, Storia d'Italia, Turín, 2007.

García Carraffa, Alberto y Arturo. Enciclopedia Heráldica. 1919, vol. 1.

Ghelli, Maria Elena, "Il viceré marchese del Carpio (1683-1687)", Archivio Storico per le province napoletane, 1933, vol. 58, pp. 80-318 y vol. 59, pp. 257-282.

Gómez, Antonio Enríquez, Academias Morales de las musas, Madrid, 1660.

Harris, Enriqueta, “The Alexander Mountain”, en Hadjinicolau, Nikos (ed.), Alexander the Great in European Art, cat. exp., Tesalónica, 1997, pp. 248-253.

Haskell, Francis, Patrons and Painters, London, 1971.

Haskell, Francis, History and its images: art and interpretation of the past, Londres, 1993.

Il Regno festeggiante: per l'entrata al governo del suo gran vicere, e capitan generale, l'ill. ${ }^{\text {mo }}$, et ecc. ${ }^{\text {mo }}$ sig. ${ }^{\text {re }}$ Don Gaspar de Haro i Gusman, marchese del Carpio, e di Licce, del Consiglio di Stato di S.M. et suo ambasciatore ord., et estraord., alla St. ${ }^{\text {ta }}$ di Innocenzo 11, Roma, 1683.

Inghirami, Francesco, Storia della Toscana, Fiesole, 1844.

John, Antony (ed.), Music for an Academic Defense (Rome, 1617), Middleton (Wisconsin), 2004.

Kusche, Maria. Der christliche Ritter und seine Dame, das Repräsentationsbildnis in ganzer Figur, Munich, 1991.

López Torrijos, Rosa, “Coleccionismo en la época de Velázquez: el marqués de Heliche”, en Velázquez y el arte de su tiempo, V jornadas de arte. CSIC, Madrid 1991, pp. 27-36.

López-Fanjul, María, “The Spanish Origins of the Marqués del Carpio’s Collection of Drawings”, Master Drawings, 2010, vol. 48, no. 4, pp. 463-481.

López-Fanjul y Díez del Corral, María, Collecting Italian Drawings in Seventeenth-Century Spain: the Marqués del Carpio's Collection, tesis doctoral inédita, The Courtauld Institute of Art, Londres, 2011.

Malcolm, Alastair, Don Luis de Haro and the Political Elite of the Spanish Monarchy in the Mid-Seventeenth Century, tesis doctoral inédita, Oxford University, 1999.

Manfrè, Valeria, Mauro, Ida. "Rievocazione dell'immaginario asburgico: le serie dei ritratti di viceré e governatori nelle capitali dell'Italia spagnola", Ricerche sul' 600 napoletano, 2010-2011, pp. 107-135.

Maravall, José Antonio, "La literatura de emblemas en el contexto de la sociedad barroca", en Teatro y literatura en la sociedad barroca, Madrid, 1972.

Marías, Fernando, "Don Gaspar de Haro, Marqués del Carpio, coleccionista de dibujo", en Colomer, José Luis (ed.), Arte y diplomacia de la monarquía hispánica en el siglo XVII, Madrid, 2003, pp. 209-219.

Marin, Louis, Le portrait du Roy, París, 1981.

Martín, María Teresa, La monarquía española en la pintura. Los Austrias, Barcelona, 2004.

Mínguez, Víctor, "El Rey Solar en la emblemática hispánica”, en Los reyes solares, Castellón, 2001, pp. 109-126

Morán, Miguel, Portús, Javier, El arte de mirar. La pintura y su público en la España de Velázquez, Madrid, 1997.

Moreno, Fernando, "La visión emblemática del gobernante virtuoso", Goya, 177-188, 1985, pp. 17-26.

Muñoz, María Jesús, "Las compras de pintura italiana realizadas en la almoneda de Carlos I de Inglaterra por Alonso de Cárdenas", en Actas del XI Congreso Español de Historia del Arte "El Mediterráneo y el Arte Español", Valencia, 1996, pp. 198-201.

Muñoz, María Jesús. El mercado español de pinturas en el siglo XVII, Madrid, 2008.

Nicolini, Fausto, Aspetti della vita italo-spagnola, Nápoles, 1934.

Páez Ríos, Elena, "Iconografía hispana: catálogo de los retratos de personajes españoles de la Biblioteca Nacional"; Madrid, 1966-1970.

Pascual Chenel, Álvaro, El retrato de Estado durante el reinado de Carlos II: Imagen y propaganda, Madrid, 2010.

Paz, Julián, “Campaña del Marqués del Carpio, D. Gaspar de Haro y Guzmán, Virrey de Nápoles, contra los bandidos del Abruzzo en 1684”, Revista de archivos, bibliotecas y museos, 1903, VII, pp. 247-259 y $395-$ 406.

Pérez Preciado, José Juan, El marqués de Leganés y las artes, tesis inédita, Universidad Complutense, Madrid, 2009.

Arch. esp. arte, LXXXVI, 344, OCTUBRE-DICIEMBRE 2013, 291-310, ISSN: 0004-0428 
Pinto, Francisco, Oratione funerale nella morte dell'Eccllentiss.mo Sig.re D. Gasparre d'Haro Marchese del Carpio, Conte Duca d'Olivares, \&c. Vicerè, e Capitan Gener. Del Regno di Nap, Nápoles, 1688.

Pisani, Massimo, "Dal ritratto classico alla nascita ed evoluzione del ritratto ufficiale cinquecentesco. Committenza a Napoli tra Sei e Settecento", en Zampino, Giuseppe, Capolavori in festa, efimero barocco a Largo di Palazzo (1683-1759), cat. exp., Palazzo Reale, Nápoles, 1997, pp. 55-72.

Ponce de Soto, Manuel, Memorial de las tres Parténopes dedicado al excelentísimo señor d. Gaspar de Haro y Guzman marques del carpio, Nápoles, 1683.

Portús, Javier, Pintura y pensamiento en la España de Lope de Vega, Hondarribia, 1999.

Portús, Javier, El retrato español: del Greco a Picasso, cat. exp., Museo del Prado, Madrid, 2004.

Prosperi Valenti Rodinò, Simonetta, "Additions to the Drawings Collection of the Marqués del Carpio", Master Drawings, 2008, 46, no. 1, pp. 3-33.

Rice, Louise, "Pietro da Cortona and the Roman Baroque Thesis Print", en Frommel, Christoph, Schütze, Sebastian (eds.), Pietro da Cortona 1597-1669. Atti del convegno internazionale (Roma e Firenze 12-15 novembre 1997. Milán, 1999, pp. 189-200.

Salerno, Luigi, Piazza di Spagna, Nápoles, 1967.

Sinibaldi, Carlo Andrea, Le felicità di Partenope per la meritata elezzione di vicere di Napoli dell'illustrissimo, \& eccellentissimo signore don Gasparo de Har, e Guzman march. del Carpio, duca di Montoro, conte-duca d'Oliuares, Faenza, 1682.

Soler, Álvaro, El arte del poder. La Real Armería y el retrato de corte, cat. exp., Museo del Prado, Madrid, 2010.

Válgoma, Dalmiro, Mecenas de libros: su heráldica y nobleza, Burgos, 1966.

Villalba, Bartolomé de, Sangre triunfal de la Iglesia, Madrid, 1672.

Virgilio, Publio, Eneida, México, 2006.

Visceglia, Maria Aantonietta (ed.), Diplomazia e politica della Spagna a Roma. Figure di ambasciatori, Roma, 2008.

Wallace, Richard (et al.), The Illustrated Bartsch. Italian Masters of the Seventeenth Century, Nueva York, 1990.

Zafra, Rafael. Azanza, José Javier (eds.), Emblemata aurea. La emblemática en el arte y la literatura del Siglo de Oro, Madrid, 2000.

Zampino, Giuseppe, Capolavori in festa, efimero barocco a Largo di Palazzo (1683-1759), cat. exp., Palazzo Reale, Nápoles, 1997.

Fecha de recepción: 25-VI-2011

Fecha de aceptación: 19-IX-2011 